\title{
Carbohydrate and Lipid Metabolism in Endogenous Hypercortisolism: Shared Features with Metabolic Syndrome $X$ and NIDDM
}

\author{
TheOdore C. FRIEDMAN $* * *, * * * *$, George MASTORAKOS**, ThELMA D. NEWMAN $* *$, \\ NANCY M. MULLEN**, ElLEN G. HORTON**, Rene COSTELLO***, \\ Nicholas M. PAPADOPOULOS***, AND GEORgE P. CHROUSOS** \\ *Laboratory of Developmental Neurobiology and **Developmental Endocrinology Branch, NICHD, and \\ ***Clinical Pathology Dept., Clinical Center; NIH, Bethesda, MD 20892, and \\ ****The Division of Endocrinology, Department of Medicine, Cedars-Sinai Medical \\ Center-University of California School of Medicine, Los Angeles, CA 90048, USA
}

\begin{abstract}
Carbohydrate and lipid metabolism was cross-sectionally assessed in 16 patients with endogenous hypercortisolism (endogenous Cushing syndrome). Five patients (31\%) had fasting glucose levels over $6.6 \mathrm{mmol} / l$ and a HbA1c over $7.5 \%$. Six patients $(38 \%)$ had diabetes mellitus based on an abnormal $75 \mathrm{~g}$ oral glucose tolerance test (OGTT) and two additional patients (13\%) had impaired glucose tolerance based on an OGTT. Compared to obese individuals, patients with Cushing syndrome had an elevated glucose but no elevated insulin response to the OGTT. Regression analysis showed positive correlations between 24-h urinary free cortisol (UFC) and fasting blood glucose $(P<0.0005)$, UFC and OGTT glucose area under the curve (AUC) $(P<0.01)$, and UFC and HbAic $(P<0.005)$. UFC levels were negatively correlated $(P<0.05)$ with OGTT insulin AUC and insulin/glucose ratios. Eleven $(69 \%)$ patients required anti-hypertensive therapy for blood pressure control. Total cholesterol and triglycerides were elevated in patients with Cushing syndrome compared to obese controls, while LDL and HDL cholesterol, and Lp(a) were similar in the two groups. We conclude that impaired glucose tolerance and/or diabetes in patients with endogenous Cushing syndrome is due to the hyperglycemic effects of cortisol with relative insulinopenia. Thus, Cushing syndrome shares features with both the Metabolic Syndrome X and NIDDM, including impaired glucose uptake, hyperlipidemia and hypertension. However, in Cushing syndrome, a relative insulinopenia occurs, while in Metabolic Syndrome $X$ and NIDDM, insulin excess is observed. In Cushing syndrome, as the hypercortisolemia exacerbates, insulinopenia becomes more paramount, suggesting that cortisol exerts a direct or indirect "toxic" effect on the $\beta$-cell.
\end{abstract}

Key words: Cushing's, Diabetes, Insulin, Syndrome X, Lp(a)

(Endocrine Journal 43: 645-655, 1996)

THE complications of hypercortisolism are protean. While some of the manifestations of glucocorticoid excess are directly due to corticos-

Received: December 18, 1995

Accepted: June 21, 1996

Correspondence to: Dr. Theodore C. FRIEDMAN, CedarsSinai Medical Center, B-131, 8700 Beverly Blvd, Los Angeles, CA 90048, USA teroids, other manifestations may be due to steroid-induced alterations of other hormones. Patients with Cushing syndrome have many cardiovascular complications [1] and it is thought that vascular disease is responsible for the high mortality rate of patients [2]. It is unclear whether the vascular complications are due directly to glucocorticoids or are secondary to the hyperglycemia and presumed hyperinsulinemia found in patients 
with glucocorticoid excess. Alternatively, as both glucocorticoids and insulin affect lipid metabolism, the cardiovascular disease seen in patients with Cushing syndrome may be due to a direct effect of steroids on such factors as lipid metabolism or coagulopathy or an indirect effect of other hormones (i.e. insulin, catecholamines) on these factors. We therefore examined the relationship between endogenous glucocorticoid excess (Cushing syndrome) and carbohydrate and lipid metabolism. We postulated that understanding the prevalence and interplay of diabetes and dyslipidemia in patient with Cushing syndrome would provide insight into the morbidity and mortality of the disorder.

Both exogenous and endogenous glucocorticoids cause diabetes and/or impaired glucose tolerance [3-6]. Patients with endogenous hypercortisolism have been reported to have an increased incidence of carbohydrate intolerance [1, 2, 7-11], although the exact incidence and nature of this disorder has remained unclear. Previous studies reporting the incidence of impaired carbohydrate tolerance in patients with Cushing syndrome have been retrospective $[1,2,7,9]$ or have examined fasting hyperglycemia without performing an oral glucose tolerance test (OGTT) to make the diagnosis of diabetes mellitus [1, 12]. Those studies performing OGTTs, on the other hand, have used a non-standard amount of glucose load [2] and have often measured only glucose response and not insulin response $[2,7,8]$ and have not examined the relationship between the degree of hypercortisolism and the glucose and insulin response to OGTT. Studies with limited numbers of patients have suggested that patients with endogenous or exogenous hypercortisolism exhibit insulin resistance [13-17]. We were interested in examining carbohydrate metabolism in consecutively admitted patients with pathologically proven endogenous Cushing syndrome by measuring plasma levels of fasting glucose, $\mathrm{HbA}_{1 \mathrm{c}}$ and levels of glucose and insulin before and during a $75 \mathrm{~g}$ OGTT and correlating these parameters with indices of hypercortisolism.

Long term administration of glucocorticoids results in elevated cholesterol and triglyceride levels $[18,19]$ and there is a correlation between plasma cortisol and coronary atherosclerosis in patients undergoing coronary angiography [20]. Additionally, patients with Cushing syndrome [21] as well as patients with diabetes mellitus [22] have elevated serum lipid levels. Thus, Cushing syndrome greatly resembles Syndrome $X$ (central adiposity, insulin resistance, hyperlipidemia and hypertension), first described by Reaven [23]. The hyperlipidemia in patients with hypercortisolism may be a direct effect of glucocorticoids or secondary to elevated glucose or insulin levels. The relative contributions of these hormones to cardiovascular risk have not been examined. Lipoprotein (a) [Lp (a)], an independent risk factor for atherosclerosis [24], is reduced in patients receiving glucocorticoid therapy for rheumatic disease [25]. Its levels have not been examined in patients with endogenous hypercortisolism. We therefore measured lipids and Lp(a) levels in patients with Cushing syndrome.

\section{Subjects and Methods}

\section{Subjects and protocol}

Our main group (group 1) of patients with Cushing syndrome was studied for diabetic and lipid complications in a cross-sectional manner. This group consisted of sixteen consecutive patients (14 females, 2 males) suspected of having Cushing syndrome and studied during their first admission to an inpatient ward at the National Institutes of Health (NIH) for diagnosis and treatment. Patient characteristics are summarized in Table 1. No patients were taking insulin, oral hypoglycemic medication or medicines affecting the hypothalamic-pituitary-adrenal axis at the time of the study. Ages ranged from 27 to $67 \mathrm{y}(41.9 \pm 10.3 \mathrm{y}$, mean \pm SD). Mean blood pressure was obtained from three consecutive morning measurements while on antihypertensive medicines. Because only trends in differences in lipid abnormalities compared to obese volunteers were seen in studies of group 1 (see "Results"), a second, larger group (group 2), consisting of patients from group 1 as well as 24 additional patients with Cushing syndrome, was studied to characterize only the lipid disorders in patients with Cushing syndrome. Thus, there were 40 patients in group 2 ( 35 females, 5 males; ages $38.3 \pm 11.6 \mathrm{y}$, range 19-70 y). In both groups, duration of the disease ranged from 1 to $30 \mathrm{y}$ as estimated by detailed medical history and the first 
Table 1. Patient characteristics

\begin{tabular}{|c|c|c|c|c|c|c|c|c|c|}
\hline Number & Diagnosis & Age & Sex & $\begin{array}{c}\text { BMI } \\
\left(\mathrm{kg} / \mathrm{m}^{2}\right)\end{array}$ & $\begin{array}{l}\text { Duration } \\
\text { (y) }\end{array}$ & $\begin{array}{l}\text { Mean UFC } \\
(\mathrm{nmol} / \mathrm{d})\end{array}$ & $\begin{array}{l}\text { Fasting GLU } \\
(\mathrm{mmol} / \mathrm{L})\end{array}$ & $\begin{array}{c}\mathrm{HbA}_{1 \mathrm{c}} \\
(\%)\end{array}$ & $\mathrm{BP}$ \\
\hline 1 & $\mathrm{CD}$ & 39 & $\mathrm{~F}$ & 43.6 & 20 & 2840 & 6.3 & 6.3 & $130 / 77$ \\
\hline 2 & $\mathrm{CD}$ & 42 & $\mathrm{~F}$ & 25.3 & 3.5 & 930 & 5.3 & 6.0 & $124 / 77$ \\
\hline 3 & $\mathrm{CD}$ & 33 & M & 43.8 & 2.5 & 3410 & 9.6 & 8.5 & $153 / 93^{1,3,4}$ \\
\hline 4 & ECTOPIC & 45 & $\mathrm{~F}$ & 31.0 & 4.0 & 3390 & 9.7 & 8.8 & $143 / 98^{1,2,4}$ \\
\hline 5 & $\mathrm{CD}$ & 41 & $\mathrm{~F}$ & 28.1 & 5.0 & 1920 & 5.2 & 6.2 & $114 / 69$ \\
\hline 6 & $C D$ & 46 & $\mathrm{~F}$ & 38.6 & 3.5 & 550 & 4.5 & 5.6 & $127 / 84^{1,4}$ \\
\hline 7 & $\mathrm{CD}$ & 67 & $\mathrm{~F}$ & 29.4 & 8.0 & 1360 & 4.4 & 6.4 & $140 / 81^{1,3,4}$ \\
\hline 8 & ECTOPIC & 56 & $\mathrm{~F}$ & 22.8 & 5.0 & 3500 & 9.8 & 8.5 & $206 / 95^{1,2,4}$ \\
\hline 9 & $\mathrm{CD}$ & 43 & $\mathrm{~F}$ & 60.0 & 30 & 640 & 8.1 & 7.7 & $152 / 83^{1,2,4}$ \\
\hline 10 & $\mathrm{CD}$ & 41 & $\mathrm{~F}$ & 44.9 & 1.0 & 1130 & 5.3 & 6.7 & $137 / 92^{1,4}$ \\
\hline 11 & $C D$ & 52 & $\mathrm{~F}$ & 31.1 & 1.0 & 1540 & 5.0 & & $140 / 88^{1,2}$ \\
\hline 12 & $\mathrm{CD}$ & 44 & $\mathrm{~F}$ & 31.8 & 5.0 & 1000 & 4.8 & 5.6 & $140 / 86^{3,4}$ \\
\hline 13 & $\mathrm{CD}$ & 33 & $\mathrm{~F}$ & 38.3 & 9.5 & 3230 & 10.1 & 9.7 & $142 / 99^{1,2}$ \\
\hline 14 & $\mathrm{CD}$ & 27 & $\mathrm{~F}$ & 36.9 & 2.0 & 1580 & 5.1 & 6.6 & $125 / 80$ \\
\hline 15 & $\mathrm{CD}$ & 30 & $\mathrm{~F}$ & 31.9 & 3.0 & 1260 & 5.6 & 6.4 & $133 / 81$ \\
\hline 16 & PPMAD & 32 & M & 26.4 & 10 & 2090 & 5.5 & 5.8 & $142 / 88^{1}$ \\
\hline Mean & & 44 & & 35.2 & 7.1 & 1900 & 6.5 & 7.0 & \\
\hline SEM & & 3.6 & & 2.4 & 1.9 & 260 & 0.5 & 0.34 & \\
\hline $\mathrm{nl}$ & & & & & & $<250$ & $4.4-6.6$ & $5.4-7.5$ & \\
\hline
\end{tabular}

Group 1 patients (see "Subjects and Methods"). CD, Cushing disease; ECTOPIC, ectopic ACTH syndrome; PPMAD, primary pigmented micronodular adrenal disease; BMI, body mass index; GLU, glucose; HbA1c, hemoglobin $A_{1 C}$; UFC, urinary free cortisol; BP, mean of blood pressure taken on 3 consecutive mornings while the patient was on the following anti-hypertensive medicines. ${ }^{1}$ Angiotensin-converting enzyme inhibitor. ${ }^{2}$ Calcium-channel blocker. ${ }^{3}$ Beta-blocker. ${ }^{4}$ Other anti-hypertensive agent.

appearance of symptoms related to the disease (weight gain, proximal muscle weakness, striae, etc.). All patients underwent a complete history and physical examination at which time the signs and symptoms of Cushing syndrome were recorded. The biochemical documentation of endogenous hypercortisolism was based on lack of circadian rhythmicity in plasma cortisol concentrations and increased levels of 24-h urinary free cortisol (UFC) and 17-hydroxysteroid/creatinine (17OHS/CR.) excretion. UFC was measured by radioimmunoassay after extraction of cortisol from the urine with an organic solvent [26] and 17OHS excretion was measured by a modification of the Porter-Silber method [27]. Twenty-four h UFC and 17OHS/CR. excretion was determined as the average of multiple measurements [3-10]. All the patients were hypercortisolemic (UFC $>276 \mathrm{nmol} / 24 \mathrm{~h}$ ) at the time of the study and had pathologically proven Cushing syndrome (Group 1; 13 with Cushing disease, 2 with the ectopic ACTH syndrome, and 1 with primary pigmented micronodular adrenal disease in the context of Carney's syndrome, Group 2; 33 patients with Cushing disease, 1 with an adrenal adenoma, 6 with the ectopic ACTH syndrome, and 1 with primary pigmented micronodular adrenal disease in the context of Carney's syndrome).

Patients in Group 2 were compared to 20 obese patients of similar age [all with body-mass indices (BMI) greater than $27 \mathrm{~kg} / \mathrm{m}^{2}$ ] (19 females, 1 male, ages $35.1 \pm 6.9 \mathrm{y}$, mean $\pm \mathrm{SD}$, range $24-46 \mathrm{y}$ ) admitted to an inpatient ward at the National Institutes of Health for studying their hypothalamic-pituitary-adrenal axis. All patients were eucortisolemic (UFC $<276 \mathrm{nmol} / 24 \mathrm{~h}$ ). These obese patients had similar BMI $\left(36.4 \pm 1.0 \mathrm{~kg} / \mathrm{m}^{2}\right.$, mean \pm SEM) as the patients with Cushing syndrome $\left(33.1 \pm 1.9 \mathrm{~kg} / \mathrm{m}^{2}, P=\right.$ N.S. $)$ and were selected to have obesity without concommitant medical problems such as cardiovascular or thyroid disease or diabetes. 


\section{Basal levels of biochemical parameters and OGTT}

After a $10 \mathrm{~h}$ fast, patients in Group 1 underwent phlebotomy for plasma glucose on three occasions, as well as for measurement of serum cholesterol, $\mathrm{HDL}$-cholesterol, triglycerides and $\mathrm{HbA}_{1 \mathrm{c}}$. On a separate occasion, after a $10 \mathrm{~h}$ fast, patients underwent a $75 \mathrm{~g}$ OGTT. Plasma was drawn for glucose, and serum was drawn for insulin at times 0,30 , $60,90,120$ and $180 \mathrm{~min}$ from an indwelling venous catheter. Glucose was measured by glucose oxidase assay and insulin was measured by RIA as previously described [28]. The time-integrated glucose and insulin secretion area under the curve (AUC) were obtained by summing all the points on the OGTT curve and multiplying by time (trapezoidal rule). As glucose and insulin responses to a standard OGTT in both normal weight volunteers and obese individuals have been well described in the literature, a range of normal responses for both patient populations was calculated from the reports from 4 different laboratories with senior investigators well recognized for expertise in the field of diabetes [29-32]. For each study, the maximal and minimal values at each time after glucose administration was interpolated from the published figures as the mean + SEM and mean SEM, respectively. The range of responses was then calculated from the four studies by taking the highest maximal value and the lowest minimal value at each time point. In these four studies, none of the normal weight or obese individuals had diabetes or were taking medications known to affect carbohydrate metabolism. In the study by Simonson et al. [29], the younger normal weight group consisted of 9 individuals ( $5 \mathrm{M}, 4 \mathrm{~F}$ ), age $25 \pm 3$ y (mean \pm SD), weight $59 \pm 2 \mathrm{~kg}$ (mean \pm SEM) (BMI not given) and the obese group consisted of 9 individuals ( $2 \mathrm{M}, 7 \mathrm{~F})$, age $60 \pm 12 \mathrm{y}$, weight $84 \pm 5 \mathrm{~kg}$. In the study by O'Shaughnessy et al. [30], the premenopausal normal weight group consisted of 7 individuals $(7 \mathrm{~F})$, age $27 \pm 5 \mathrm{y}, \mathrm{BMI} 22.1 \pm 0.8 \mathrm{~kg}$ / $\mathrm{m}^{2}$ (mean $\pm \mathrm{SEM}$ ), and the pre-menopausal obese group consisted of 9 individuals ( $9 \mathrm{~F}$ ), age $32 \pm 6 \mathrm{y}$, BMI $34.2 \pm 0.5 \mathrm{~kg} / \mathrm{m}^{2}$. There were no values given for $180 \mathrm{~min}$ after glucose administration in this report. In the study by Groop et al. [31], the normal weight group consisted of 14 individuals (5 $\mathrm{M}, 9 \mathrm{~F})$, age $48 \pm 19 \mathrm{y}, \mathrm{BMI} 22.9 \pm 0.6 \mathrm{~kg} / \mathrm{m}^{2}$, and the obese group consisted of 17 individuals $(9 \mathrm{M}, 8$ F), age $53 \pm 12 \mathrm{y}, \mathrm{BMI} 30.5 \pm 1.1 \mathrm{~kg} / \mathrm{m}^{2}$. In the study by Garvey et al. [32], the normal weight group consisted of 12 individuals (12 M), age $35 \pm$ $10 \mathrm{y}$, BMI $25.1 \pm 0.5 \mathrm{~kg} / \mathrm{m}^{2}$, and the obese group consisted of 11 individuals ( $8 \mathrm{M}, 3 \mathrm{~F}$ ), age $37 \pm 10$ $\mathrm{y}$, BMI $33.4 \pm 0.9 \mathrm{~kg} / \mathrm{m}^{2}$.

After a $12 \mathrm{~h}$ fast, patients in Group 2 underwent phlebotomy for measurement of serum cholesterol, HDL-cholesterol, triglycerides and Lp (a). LDL cholesterol was calculated using the Friedenwald formula: LDL cholesterol=total cholesterol - HDL cholesterol - (triglycerides/5). Lp (a) was measured using an enzyme immunoassay kit (Terumo Medical Corp., Elkton, MD) as described [33].

\section{Statistical analyses}

Unpaired Student $t$-tests were used to compare parameters between patients with Cushing syndrome and obese individuals. Measures assessing cortisol excretion (UFC and 17-OHS/CR.) were correlated with glycemic indices (mean fasting glucose, glucose AUC, insulin AUC, insulin AUC/glucose $\mathrm{AUC}$, and $\mathrm{Hb} \mathrm{A}_{1 \mathrm{C}}$ ) using the Statview (Abacus Concepts, Inc, Berkeley, CA) software for Macintosh computers. Statistically significant differences were considered at $P<0.05$.

\section{Results}

Plasma levels of glycemic indices of carbohydrate metabolism before and during OGTT in patients with endogenous Cushing syndrome

A summary of the glycemic indices of patients in Group 1 with Cushing syndrome is listed in Table 1. The mean \pm SEM for fasting glucose and $\mathrm{HbA}_{1 \mathrm{c}}$ were $6.5 \pm 0.5 \mathrm{mmol} / l$ and $7.0 \pm 0.3 \%$, respectively (Table 1 ). Five (31\%) of the patients had an elevated fasting glucose $(>7.7 \mathrm{mmol} / \mathrm{l})$ on at least two of three occasions and a $\mathrm{HbA}_{1 \mathrm{c}}>7.5 \%$. None of the other patients had a fasting glucose level above $7.7 \mathrm{mmol} / l$ on any of the 3 measurements. Six (38\%) patients reached the National Diabetes Data Group [34] criteria for diabetes mellitus during a $75 \mathrm{~g}$ OGTT and an additional 2 patients (13\%) reached criteria for impaired glucose tolerance. Compared to literature values from 
normal volunteers (see "Methods" section), patients with Cushing syndrome had glucose, insulin and insulin/glucose ratios above the normal range in response to the $75 \mathrm{~g}$ glucose load during the OGTT (Fig. 1A-C). However, when compared to healthy obese individuals, patients with Cushing syndrome had glucose response above the normal range, but not insulin response or the insulin/glucose ratios.

\section{Blood pressure in patients with endogenous Cushing syndrome}

Mean blood pressure and anti-hypertensive medicines of the patients with Cushing syndrome is depicted in Table 1. Eleven (69\%) of 16 patients required anti-hypertensive medication at the time of the study.

Serum levels of lipids and lipoprotein $A$ in patients with endogenous Cushing syndrome and obese controls

Assessing the patients in group 1, there was a trend for an elevation in total cholesterol level in patients with Cushing syndrome (5.46 \pm 0.19 $\mathrm{mmol} / l, P=0.07)$ compared to obese controls (4.92 $\pm 0.22 \mathrm{mmol} / \mathrm{l})$. In the larger group of patients (Group 2; $\mathrm{n}=40)$, total cholesterol $(5.46 \pm 0.15 \mathrm{mmol} /$ $l$ vs. $4.92 \pm 0.22 \mathrm{mmol} / l ; P<0.05)$ and triglycerides were elevated $(1.77 \pm 0.15 \mathrm{mmol} / \mathrm{l}$ vs. $1.30 \pm 0.13$ $\mathrm{mmol} / l ; P<0.05)$ in patients with Cushing syndrome compared to obese individuals of similar age and BMI (Table 2). Lp (a) and HDL and LDL cholesterol were not different between patients with Cushing syndrome and obese individuals.

\section{Correlations between parameters assessing levels and/or duration of cortisol excretion with indices of carbohydrate and lipid metabolism}

To assess the importance of the amount of circulating glucocorticoids on carbohydrate metabolism, we examined the correlations between parameters assessing levels of cortisol with indices of carbohydrate metabolism. UFC was strongly correlated to mean fasting glucose, $\mathrm{HbA}_{1 \mathrm{c}}$ and glucose AUC during OGTT (Table 3, Fig. 2A). 17OHS/CR. was also significantly correlated with mean fasting glucose, $\mathrm{HbA}_{1 \mathrm{C}}$ and glucose AUC (Table 3). A negative, significant correlation was obtained when
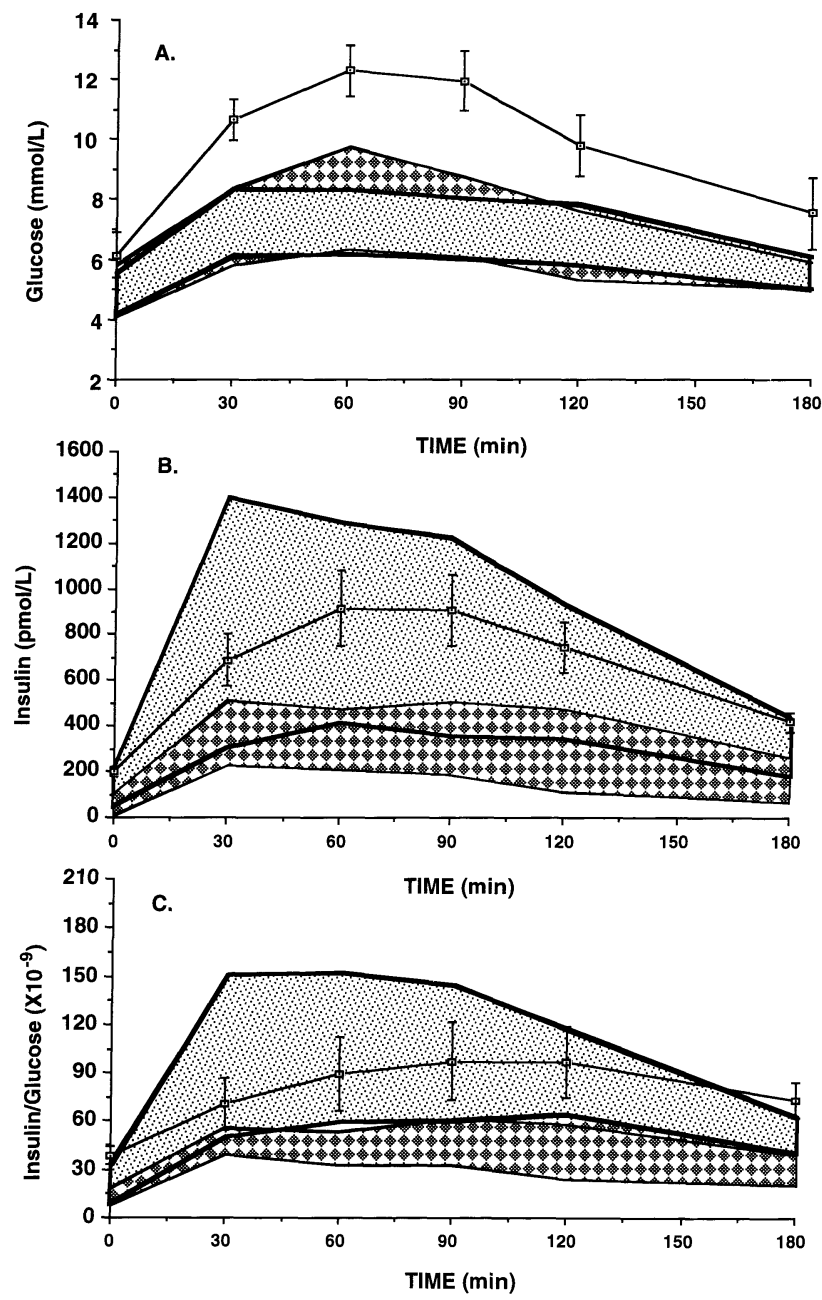

Fig. 1. Glucose (A), insulin (B) and insulin/glucose ratio (C) during an oral glucose tolerance test (OGTT) in patients with Cushing syndrome. The mean \pm SEM for the glucose, insulin and insulin/glucose ratio responses at each time point following oral administration of $75 \mathrm{~g}$ OGTT for 16 patients with Cushing syndrome is depicted. indicates the range of responses for normal individuals and indicates the response for obese patients [taken from [29-32]] as described in the "Methods" section.

UFC or 17OHS/CR. was correlated with insulin AUC (Fig. 2B, Table 3) or insulin AUC/glucose AUC ratio during OGTT (Table 3). There was no correlation between $\mathrm{BMI}$ and glycemic parameters or BMI and UFC or 17OHS/CR. (data not shown), demonstrating that the correlation between UFC and glycemic parameters was not due to patients with more severe Cushing syndrome having a higher BMI and subsequently being more hyper- 
Table 2. Serum levels of lipoproteins in patients with Cushing syndrome and obese controls

\begin{tabular}{lccc}
\hline & Cushing syndrome & Obesity & $P$ \\
\hline Total cholesterol & $5.46 \pm 0.15 \mathrm{mmol} / l$ & $4.92 \pm 0.22 \mathrm{mmol} / l$ & $<0.05$ \\
HDL cholesterol & $1.31 \pm 0.06 \mathrm{mmol} / l$ & $1.19 \pm 0.07 \mathrm{mmol} / l$ & N.S. \\
LDL cholesterol & $3.43 \pm 0.16 \mathrm{mmol} / l$ & $3.13 \pm 0.19 \mathrm{mmol} / l$ & N.S. \\
Triglycerides & $1.77 \pm 0.15 \mathrm{mmol} / l$ & $1.30 \pm 0.13 \mathrm{mmol} / l$ & $<0.05$ \\
Lp (a) & $2.16 \pm 0.49 \mathrm{mg} / l$ & $2.66 \pm 0.51 \mathrm{mg} / l$ & N.S. \\
\hline
\end{tabular}

Mean \pm SEM from 37 (total cholesterol), 29 (HDL and LDL cholesterol), 30 (triglycerides) and $24[\mathrm{Lp}(\mathrm{a})]$ patients with Cushing syndrome and 20 patients with obestiy. N.S., not significant.

Table 3. Correlations between cortisolemic and diabetic/lipidemic parameters in patients with Cushing syndrome

\begin{tabular}{llrl}
\hline Dependent variable & Independent variable & \multicolumn{1}{c}{$\mathrm{r}$} & $P$ \\
\hline UFC & Mean Fasting Glucose & 0.80 & 0.0004 \\
UFC & Glucose AUC & 0.63 & 0.009 \\
UFC & Insulin AUC & -0.50 & 0.04 \\
UFC & INS./GLU.AUC & -0.52 & 0.03 \\
UFC & HbAic & 0.73 & 0.002 \\
UFC & Fasting insulin & -0.12 & $\mathrm{~N} . S$. \\
17OHS/CR. & Mean Fasting Glucose & 0.57 & 0.03 \\
17OHS/CR. & Glucose AUC & 0.51 & 0.04 \\
17OHS/CR. & Insulin AUC & -0.57 & 0.02 \\
17OHS/CR. & INS./GLU.AUC & -0.54 & 0.03 \\
17OHS/CR. & HbAic & 0.62 & 0.01 \\
Duration $\times$ UFC & Mean Fasting Glucose & 0.40 & N.S. \\
Duration $\times$ UFC & Glucose AUC & 0.29 & N.S. \\
Duration $\times$ UFC & Insulin AUC & -0.16 & N.S. \\
Duration $\times$ UFC & INS./GLU.AUC & -0.20 & N.S. \\
Duration $\times$ UFC & HbAic & 0.25 & N.S. \\
Mean Fasting Glucose & Insulin AUC & -0.62 & 0.01 \\
HbAic & Insulin AUC & -0.64 & 0.01 \\
\hline
\end{tabular}

UFC, urinary free cortisol; 17OHS, 17-hydroxysteroid; CR., creatinine; BMI, body mass index; INS., insulin; GLU., glucose; $\mathrm{HbA}_{1 \mathrm{C}}$, hemoglobin $\mathrm{A}_{1} \mathrm{C}$; $\mathrm{AUC}$, area under the curve; N.S., not significant.

glycemic.

The importance of the duration of cortisol secretion on carbohydrate metabolism was also assessed by correlating the product of duration of Cushing syndrome and UFC excretion with glycemic indices. No significant correlations between duration of disease $\times$ UFC and mean fasting glucose, $\mathrm{HbA1C}$, glucose AUC, insulin AUC or insulin AUC/glucose AUC ratio were found when a linear correlation was used. Inspection of the scatterplot (Fig. 2C) showed an exponential decline of insulin AUC and an exponential increase of glucose AUC with an increase in duration of disease $\times$ UFC. In- deed, when this was fit to a 2nd order polynomial equation, a significant correlation was found. Similarly, although a linear correlation between duration of disease $\times 17 \mathrm{OHS} / \mathrm{CR}$. and glycemic parameters was not found, a 2nd order correlation was found between duration of disease $\times 17 \mathrm{OHS}$ / $\mathrm{CR}$. and glucose or insulin AUC (data not shown). Duration of the disease itself was not correlated with any of the glycemic indices tested (data not shown). Thus, initially the product of duration $x$ severity of disease leads to a rapid increase in the glucose response to glucose load and a rapid decrease in the insulin response to the glucose load. 

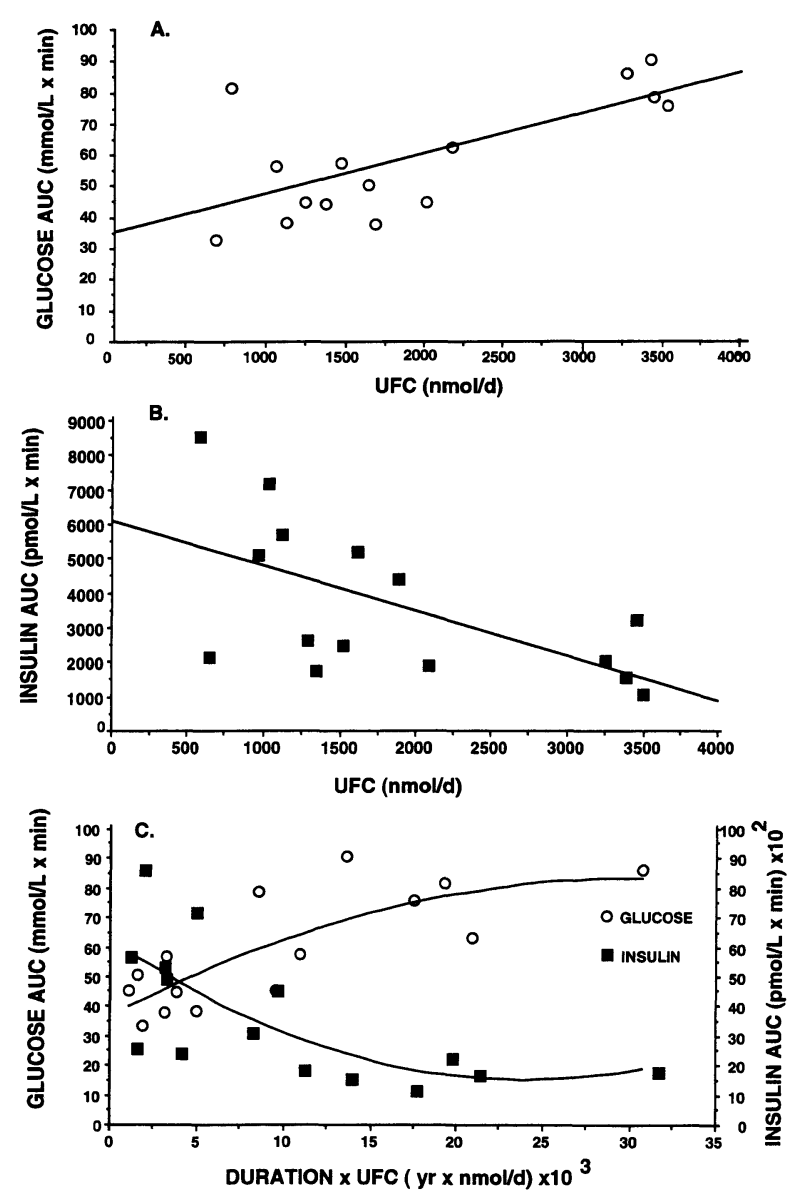

Fig. 2. Correlations between UFC excretion and glucose area under the curve (AUC) (A), UFC excretion and insulin AUC (B) and duration $\times$ UFC excretion and glucose AUC and insulin AUC (C). AUC was calculated by summing the glucose and insulin responses to a $75 \mathrm{~g}$ oral OGTT. A linear correlation was fitted to (A) $(\mathrm{r}=0.63 ; P<0.01)$ and $(\mathrm{B})(\mathrm{r}=-0.54$; $P<0.05)$ and a second order polynomial fitted to $(C)$ (glucose, $\mathrm{r}=0.79 ; P<0.005$, insulin, $\mathrm{r}=-0.69, P<0.05$ ).

With a further increase in the product of duration $\times$ severity of disease, there was only a slight increase in the glucose and slight decrease in the insulin response to the glucose load.

We also correlated UFC excretion with total cholesterol, HDL cholesterol, triglycerides and Lp (a). There was no significant correlation between any of these parameters (data not shown) indicating that severity of Cushing syndrome did not result in worsening hyperlipidemia.

\section{Discussion}

We found that $38 \%$ of patients with endogenous Cushing syndrome were diabetic by fasting glucose or OGTT criteria, while $50 \%$ had diabetes mellitus or impaired carbohydrate tolerance. This is less than the $94 \%$ of patients reported by Plotz et al. [7] to have impaired glucose tolerance (definition not stated) and by Pupo et al. [8], who performed OGTTs in 12 patients with Cushing syndrome and found that 11 of them had glucose responses consistent with diabetes but only 2 had elevated baseline glucose levels. Ross et al. [2] used a $50 \mathrm{~g}$ oral glucose test and found that $50 \%$ of the patients had a glucose response greater than 6.5 $\mathrm{mmol} / \mathrm{l}(280 \mathrm{mg} / \mathrm{d} l)$. Modigliani et al. [10] gave a glucose dose of $1 \mathrm{~g} / \mathrm{kg}$ and found impaired glucose tolerance in 12 of 15 patients with Cushing syndrome but hyperinsulinemia in only 5 patients. Takeda et al. [35] performed OGTTs in 9 patients with Cushing's syndrome and found elevated glucose but not insulin areas under the curve. Comparison with these earlier studies may be limited by the fact that they used different regimens of glucose administration and had different criteria for diabetes/impaired glucose tolerance.

We found an elevated glucose but not insulin response to the glucose load in patients with Cushing syndrome compared to obese non-Cushingoid individuals. Normal volunteers who received glucocorticoids also developed hyperglycemia [15, 36, 37] most likely by a stimulation of hepatic gluconeogenesis [38, 39]. The mechanism of glucocorticoid-induced hyperglycemia has been studied in a small number of patients with Cushing syndrome. Bowes et al. [40] found that glucose metabolic clearance and glucose turnover rate were decreased in patients with Cushing syndrome and suggested that the primary defect is a reduction in glucose utilization, causing elevated insulin levels and presumably a restriction of hepatic glucose production. Page et al. [17] used a frequently sampled intravenous glucose tolerance test and found that subjects with Cushing disease have reduced insulin sensitivity, reduced non-insulin mediated glucose disposal and enhanced insulin secretion. However, Saunders et al. [14] found that glucose production and utilization were higher in five patients with Cushing syndrome. Nosadini et al. [16] 
used a euglycemic clamp procedure in five patients with Cushing syndrome and found that they exhibited a decreased maximal glucose disposal suggestive of a post-receptor defect.

In contradistinction to these studies, we did not find either elevated basal or post-glucose load levels of insulin in patients with Cushing syndrome compared to obese individuals. While truncal obesity in noncushingoid subjects has been previously correlated with insulin resistance [41, 42], our study demonstrates that the hypercortisolemia of endogenous Cushing syndrome per se does not cause elevated insulin concentrations in plasma. Cushing syndrome resembles Syndrome $X$ in that both syndromes are denoted by central adiposity, impaired glucose uptake, hyperlipidemia and hypertension. In both syndromes, an increase in cardiovascular mortality is noted [1, 43, 44]. In fact, two studies examining noncushingoid patients with central adiposity who resemble Syndrome $X$, found an activation of the hypothalamic-pituitary adrenal axis, with elevated urinary cortisol excretion $[45,46]$. Our study, however, demonstrates that hyperinsulinemia is not paramount in Cushing syndrome, while it is the sine qua non of Syndrome $X$. The finding of hypertension in $69 \%$ of the patients with Cushing syndrome is also consistent with Syndrome X.

We found that the more severe the hypercortisolism, the higher the basal and glucose response to OGTT, but the lower the insulin response to OGTT and the lower the insulin/glucose ratio in response to the glucose load. This is suggestive of glucosedependent induction of relative insulinopenia. The drop in insulin AUC, when correlated with duration $\times$ severity of hypercortisolism exhibited an initial decrease followed by only a slight decline with further duration $\times$ severity of hypercortisolism (Fig. 2C). This suggests an adaptive process, whereby initially glucocorticoids, either directly or indirectly, are relatively "toxic" to the $\beta$-cell and cause a relative decrease in glucose-induced insulin secretion. This result is similar to in vitro experiments showing that glucocorticoids inhibited insulin secretion in response to glucose, arginine and leucine from isolated islets or pancreatic pieces [47-51] and to the in vivo experiments showing that a cortisol infusion in normal volunteers decreased insulin output [37]. Additionally, in the rat, the $\beta$-cells are the only cells of Langerhan's islets to contain glucocorticoid receptors [52] and dexamethasone negatively regulates insulin mRNA levels in the insulinoma cell line, HIT-15, [53] and in single rat islet cells [54]. Alternatively, in the patients with Cushing syndrome and diabetes, it is possible that the glucose damages the $\beta$-cells (glucose toxicity) [glucose AUC and $\mathrm{HbA1c}$ were negatively correlated with insulin AUC (Table 3)]. Thus, the negative correlation between UFC and insulin AUC as well as insulin/glucose ratio may be directly due to cortisol toxicity or indirectly due to glucocorticoid-induced hyperglycemia causing glucose toxicity to $\beta$-cells. The relatively low glucose levels seen in these patients (fasting glucose $<10.1 \mathrm{mmol} / \mathrm{l}$; $\mathrm{HbAlc}_{1 \mathrm{C}}<9.7 \%$ ) (Table 1) argue against the latter possiblity. It is also noteworthy that in the hypercortisolemic patients, further exposure to hypercortisolism (increased duration of disease) causes little further damage to the $\beta$-cell. This is similar to the observation of two groups of investigators who found that the impairment of carbohydrate tolerance seen in normal subjects receiving chronic glucocorticoids lessened with time $[55,56]$.

In the current study, serum levels of total cholesterol and triglycerides were mildly elevated in patients with Cushing syndrome compared to obese individuals, while LDL and HDL cholesterol and $L p(a)$ were similar in the two groups. This differs from the findings of Taskinen et al. [21] who found higher levels of total, VLDL and HDL cholesterol and total, VLDL and LDL triglycerides in patients with Cushing syndrome compared to age and weight matched controls. To our knowledge, the current study is the first to measure Lp(a) levels in patients with Cushing syndrome. We found the levels of $L p(a)$ similar in this group compared to obese controls. This finding differs from Aoki et al. [25] who found reduced levels of $L p(a)$ in patients receiving exogenous glucocorticoids. This may underscore the difference between exogenous and endogenous glucocorticoids, a result similar to the lower incidence of posterior subscapsular cataracts in patients with endogenous hypercortisolism compared to patients receiving exogenous glucocorticoids [57].

In general, we found less hyperglycemia and hyperlipidemia in patients with Cushing syndrome compared to earlier reports. Interestingly, less than half of the patients had diabetes, cholesterol and 
triglyceride levels were only slightly elevated compared to those of obese individuals, and Lp(a) levels were similar in patients with Cushing syndrome and obesity. We previously reported a low incidence of cataract formation in patients with Cushing syndrome [57]. In addition to the fact that our study was cross-sectional and used the stricter criteria for diabetes proposed in 1979 [34], we speculate on an additional reason why our study found less complications in patients with Cushing syndrome than earlier studies. Since the 1950 's-1970's, when some of the earlier studies were conducted, Cushing syndrome has become more widely known to physicians and as diagnosis and treatment for this condition has improved, more patients are treated at an earlier or less se- vere stage than before. This may explain the lack of long term complications of Cushing syndrome observed in our study and is probably a more realistic documentation of complications in current patients with Cushing syndrome.

\section{Acknowledgments}

The authors wish to thank Alain D. Baron, M. D. (University of Indiana School of Medicine), and Shlomo Melmed, M. D., Anne Peters, M. D. and Mayer Davidson, M. D. (Cedars-Sinai Medical Center) for their helpful comments concerning this manuscript.

\section{References}

1. Welbourn RB, Montgomery DA, Kennedy TL (1971) The natural history of treated Cushing's syndrome. Br J Surg 58: 1-16.

2. Ross EJ, Linch DC (1982) Cushing's syndromeKilling disease: Discriminatory value of signs and symptoms aiding early diagnosis. Lancet 2: 646-649.

3. West KM (1959) Response of the blood glucose to glucocorticoids in man. Diabetes 8: 22-28.

4. Perley M, Kipnis DM (1965) Effect of glucocorticoids on plasma insulin. $N$ Engl J Med 274: 1237-1241.

5. Conn JW, Fajans SS (1956) Symposium on diabetes. Influence of adrenal cortical steroids on carbohydrate metabolism in man. Metabolism 5: 114-127.

6. Rizza RA, Mandarino LJ, Gerich JE (1982) Cortisolinduced insulin resistance in man: Impaired suppression of glucose production and stimulation of glucose utilization due to a postreceptor defect of insulin action. J Clin Endocrinol Metab 54: 131138.

7. Plotz CM, Knowlton AI, Ragan C (1952) The natural history of Cushing's syndrome. Am J Med 13: 597-614.

8. Pupo AA, Wajchenberg BL, Schnaider J (1966) Carbohydrate metabolism in hyperadrenocorticism. Diabetes 15: 24-29.

9. Urbanic RC, George JM (1981) Cushing's disease18 years' experience. Medicine 60: 14-24.

10. Modigliani E, Strauch G, Luton JP, Bricaire H (1970) Effects du glucose et de l'arginine sur la secretion d'insuline au cours des syndromes de Cushing. Diabetologia 6: 8-14.

11. Boyle PJ (1993) Cushing's disease, glucocorticoid excess, glucocorticoid deficiency, and diabetes. Dia- betes Rev 1: 301-308

12. Cushing $H$ (1932) The basophil adenomas of the pituitary body and their clinical manifestations (pituitary basophilism). Bull of the Johns Hopkins Hospital 50: 137-195.

13. Tessari P, Inchiostro S, Biolo G, Marescotti MC, Fantin G, Boscarato MT, Merola G, Mantero F, Tiengo A (1989) Leucine kinetics and the effects of hyperinsulinemia in patients with Cushing's syndrome. J Clin Endocrinol Metab 68: 256-262.

14. Saunders J, Hall SEH, Sonsken PH (1980) Glucose and free fatty acid turnover in Cushing's syndrome. J Endocrinol Invest 3: 309-311.

15. Fantus IG, Ryan J, Hizuka N, Gordon P (1981) The effect of glococorticoids on the insulin receptor: An in vivo and in vitro study. J Clin Endocrinol Metab 52: 953-960.

16. Nosadini $R$, Del Prato $S$, Tiengo A, Valerio A, Muggeo M, Opocher G, Mantero F, Duner E, Marescotti C, Mollo F, Belloni F (1983) Insulin resistance in Cushing's syndrome. J Clin Endocrin Metab 57: 529-536.

17. Page R, Boolell M, Kalfas A, Sawyer S, Pestell R, Ward G, Alford F (1991) Insulin secretion, insulin sensitivity and glucose-mediated glucose disposal in Cushing's disease: A minimal model analysis. Clin Endocrinol 35: 509-517.

18. Stern MP, Kolterman OG, Fries JF, McDevitt HO, Reaven GM (1973) Adrenocortical steroid treatment of rheumatic diseases. Effects on lipid metabolism. Arch Intern Med 132: 97-101.

19. el-Shaboury AH, Hayes TM (1973) Hyperlipidaemia in asthmatic patients receiving long-term steroid therapy. Br Med J 2: 85-86. 
20. Troxler RG, Sprague EA, Albanese RA, Fuchs R, Thompson AJ (1977) The association of elevated plasma cortisol and early atherosclerosis as demonstrated by coronary angiography. Atherosclerosis 26: 151-162.

21. Taskinen M-R, Nikkila EA, Pelkonen $R$, Sane $T$ (1983) Plasma lipoproteins, lipolytic enzymes, and very low desity lipoprotein triglyceride turnover in Cushing's syndrome. J Clin Endocrinol Metab 57: 619-626.

22. Bagdade JD, Porte D Jr, Bierman EL (1970) Steroidinduced lipemia. A complication of high-dosage corticosteroid therapy. Arch Intern Med 125: 129 134.

23. Reaven GM (1988) Role of insulin resistance in human disease. Diabetes 37: 1595-1607.

24. Dahlen GH, Guyton JR, Attar M, Farmer JA, Kautz JA, Gotto A Jr (1986) Association of levels of lipoprotein Lp (a), plasma lipids, and other lipoproteins with ccronary artery disease documented by angiography. Circulation 74: 758-765.

25. Aoki K, Kawai S (1993) Glucocorticoid therapy decreases serum lipoprotein (a) concentration in rheumatic diseases. Intern Med 32: 382-386.

26. Ruder HJ, Guy RL, Lipsett MB (1972) A radioimmunoassay for cortisol in plasma and urine. J Clin Endocrinol Metab 35: 219-224.

27. Forman DT (1978) Measurement of urinary hydroxy-corticosteroids by column chromatography. In: Sunderman FW (ed) Manual of Procedures for the Seminar on Clinical Pathology of Cancer of the Endocrine Glands and Target Organs. Institute for Clinical Science for the Association of Clinical Scientists, Philadelphia, 135-143.

28. Sorenson RL, Steffes M, Lindall AW (1970) Subcellular localization of proinsulin to insulin conversion in isolated rat islets. Endocrinology 86: 88-96.

29. Simonson DC, Tappy L, Jequier E, Felber J-P, DeFronzo RA (1988) Normalization of carbohydrate-induced thermogenesis by fructose in insulin-resistant states. Am J Physiol 254: E201-E207.

30. O'Shaughnessy IM, Kasdorf GM, Hoffmann RG, Kalkhoff RK (1992) Does aging intensify the insulin resistance of human obesity. J Clin Endocrinol Metab 74: 1075-1081.

31. Groop LC, Saloranta C, Shank M, Bonadonna RC, Ferrannini E, DeFronzo RA (1991) The role of free fatty acid metabolism in the pathogenesis of insulin resistance in obesity and noninsulin-dependent diabetes mellitus. J Clin Endocrinol Metab 72: 96107.

32. Garvey WT, Huecksteadt TP, Matthaei S, Olefsky JM (1988) Role of glucose transporters in the cellular insulin resistance of type II non-insulindependent diabetes mellitus. J Clin Invest 81: 15281536.

33. Gorretta B, Baiocchi M, Crepaldi G (1993) Com- parison of lipoprotein A assay methods in serum and in a plasminogen-free fraction. Clin Chem Acta 218: 83-95.

34. National Diabetes Data Group (1979) Classification and diagnosis of diabetes mellitus and other categories of glucose intolerance. Diabetes 28: 1039-1057.

35. Takeda N, Yasuda K, Kitabachi AE, Horiya T, Jallepalli P, Miura K (1987) Increased insulin binding of erythrocytes and insulin sensitivity in adrenal insufficiency. Metabolism 36: 1063-1066.

36. Kitabachi AE, Jones GM, Duckworth WC (1973) Effect of hydrocortisone and corticotropin on glucose-induced insulin and proinsulin secretion in man. J Clin Endocrinol Metab 37: 79-84.

37. Dinneen S, Alzaid A, Miles J, Rizza R (1993) Metabolic effects of the nocturnal rise in cortisol on carbohydrate metabolism in normal humans. J Clin Invest 91: 2283-2290.

38. Mischke WJ, Ebers S, Boisch KH, Tamm J (1974) The influence of intravenously administered cortisol-with and without the addition of insulin or pretreatment with propranolol-on various parameters of fat and carbohydrate metabolism in blood plasma of human beings. Acta Endocrinol Suppl 186: $1-45$.

39. Iynedjian PB, Auberger P, Guigoz Y, Le Cam A (1985) Pretranslational regulation of tyrosine aminotransferase and phosphoenolpyruvate carboxykinase (GTP) synthesis by glucagon and dexamethasone in adult rat hepatocytes. Biochem $J$ 225: 77-84.

40. Bowes SB, Benn JJ, Scobie IN, Umpleby AM, Lowy C, Sonksen PH (1991) Glucose metabolism in patients with Cushing's syndrome. Clin Endocrinol 34: 311-316.

41. Pasquali $R$, Casimirri F, Cantobelli S, Melchionda N, Morselli Labate AM, Fabbri R, Capelli M, Bortoluzzi L (1991) Effect of obesity and body fat distribution on sex hormones and insulin in men. Metabolism 40: 101-104.

42. Kissebah AH, Peiris AN (1989) Biology of regional fat distribution: Relationship to non-insulin-dependent diabetes. Diabetes Metab Rev 5: 83-109.

43. Zavaroni I, Dall'Aglio E, Bonora E, Alpi O, Passeri M, Reaven GM (1987) Evidence that multiple risk factors for coronary heart disease exist in persons with abnormal glucose tolerance. Am J Med 83: 609612.

44. Reaven GM (1994) Syndrome X: Is one enough? Am Heart J 127: 1439-1442.

45. Pasquali R, Cantobelli S, Casimirri F, Capelli M, Bortoluzzi L, Flamia R, Labate AMM, Barbara L (1993) The hypothalamic-pituitary-adrenal axis in obese women with different patterns of body fat distribution. J Clin Endocrinol Metab 77: 341-346.

46. Mårin P, Darin N, Amemiya T, Andersson B, Jern 
S, Björntorp P (1992) Cortisol secretion in relation to body fat distribution in obese premenopausal women. Metabolism 41: 882-886.

47. Barseghian G, Levine R, Epps P (1982) Direct effect of cortisol and cortisone on insulin and glucagon secretion. Endocrinology 111: 1648-1651.

48. Billaudel B, Sutter BC (1981) Effect of corticosterone upon response to $\mathrm{L}(-)$ leucine of isolated rats Langerhans islets. Horm Metab Res 13: 530-531.

49. Barseghian G, Levine R (1980) Effect of corticosterone on insulin and glucagon secretion by the isolated perfused rat pancreas. Endocrinology 106: 547-552.

50. Billaudel B, Sutter BC (1979) Direct effect of corticosterone upon insulin secretion studied by three different techniques. Horm Metab Res 11: 555-560.

51. Pierluissi J, Navas FO, Ashcroft SJH (1986) Effect of adrenal steroids on insulin release from cultured rat islets of Langerhans. Diabetologia 29: 119-121.

52. Fischer B, Rausch U, Wollny P, Westphal H, Seitz J, Aumuller G (1990) Immunohistochemical localization of the glucocorticoid receptor in pancreatic $\beta$-cells of the rat. Endocrinology 126: 2635-2641.

53. Philippe J, Missotten M (1990) Dexamethasone inhibits insulin biosynthesis by destabilizing insulin messenger ribonucleic acid in hamster insulinoma cells. Endocrinology 127: 1640-1645.

54. Philippe J, Giordana E, Gjinovci A, Meda P (1992) Cyclic adenosine monophosphate prevents the glucocorticoid-mediated inhibition of insulin gene expression in rodent islet cells. J Clin Invest 90: 22282233.

55. Olefsky J, Kimmerling G (1976) Effects of glucocorticoids on carbohydrate metabolism. Am J Med Sci 271: 202-210.

56. Bastenie PA, Conard V, Franckson JRM (1954) Effect of cortisone on carbohydrate metabolism measured by the "glucose assimilation coefficient". Diabetes 3: 205-209.

57. Bouzas EA, Mastorakos G, Friedman TC, Scott MH, Chrousos GP, Kaiser-Kupfer MI (1993) Posterior subcapsular cataract in endogenous Cushing syndrome: An uncommon manifestation. Invest Ophthalmol Vis Sci 34: 3497-3500. 